\title{
Pathophysiological view of the possible restoration of movement after spinal cord transverse injury
}

\author{
Nadvornik $\mathrm{P}^{1}$, Zlatos $\mathrm{J}^{2}$, Chrastina $\mathbf{J}^{1}$ \\ Department of Neurosurgery MF MU FH St. Anna Brno, Brno, Czech Republic. nadvorpa@gmail.com
}

Spinal cord injury causing problems with limb movement affects the thoracic spinal cord in the majority of cases. The manifestation is paraplegia affecting lower extremities.

The traditional aim of emergency neurosurgical treatment is targeted towards bony spinal structures restoring the natural environment for the spinal cord inside the dural sac.

The extent of a spinal cord injury can be estimated using MRI scans or more precisely by matching the symptoms of movement disturbance according Chrastina with the stereotactic map of the spinal cord (1), containing the motoneuron location for the individual muscles or any other spinal cord structures that can be expected to participate in movement performance (2).

Maximum attention is paid to movement salvation or restoration and this is the goal of rehabilitation medicine.

Direct surgical inspection of the exposed spinal cord during emergency surgery is rarely possible and the findings are not decisive for prognostic considerations regarding movement restoration.

More frequently spinal cord thinning to less than a half of its original diameter is found after surgery for slow-growing benign tumours originating from spinal cord envelopes (e.g. meningioma) with movement abilities still preserved.

In rare cases movement restoration after spinal cord injury with paraplegia can be observed one or two years after injury. Traces of residual movements, e.g. big toe movements, are detectable immediately after injury in such cases, although subsequetly dissappear. However, this is an indication of incomplete spinal cord injury and movement restoration can almost always be expected.

The different clinical courses from permanent movement loss to restitution are undoubtely related to the variable extent of the anatomical injury of spinal cord movement structures.

As an extreme observation, the case of a 22-year-old male can be described. At the age of seven, the patient fell from a tree. Immediately after the injury he complained only of some local neck pain, but with no other problems. Fifteen years after this accident

${ }^{1}$ Department of Neurosurgery MF MU FH St. Anna Brno, Czech Republic, and ${ }^{2}$ Institute of Histology and Embryology, Faculty of Medicine, Commenius University, Bratislava, Slovakia

Address for correspondence: P. Nadvornik, MD, Department of Neurosurgery MF MU FH St. Anna Brno, Pekarska 53, CZ-656 00 Brno, Czech Republic quadriparesis quickly progressed, rapidly progressing into complete quadriplegia with respiratory and finally fatal cardiac arrest developed during a single day. An X-ray study revealed C3/4 luxation with the dislocation equal to the width of spinal canal. An emergency cautious laminectomy revealed only irregulatory arranged membranes without any traces of spinal cord structures in the compromised spinal canal.

Several presented examples provide evidence that the exact mechanism responsible for movement restoration in the injured spinal cord, od maintaining movement abilities when the spinal cord mass is lost, because of chronic cord compression.

Only spinal cord motoneurons for the individual peripheral muscles location was determined in the IX - th Rexed zone of the anterior horn of each spinal cord segment were defined with certainity (3) together with the experimental evidence (4) that reticulospinal tract stimulation at the mesencephalic level elicits different limb movements, although this tract has no direct connection to the motoneurons.

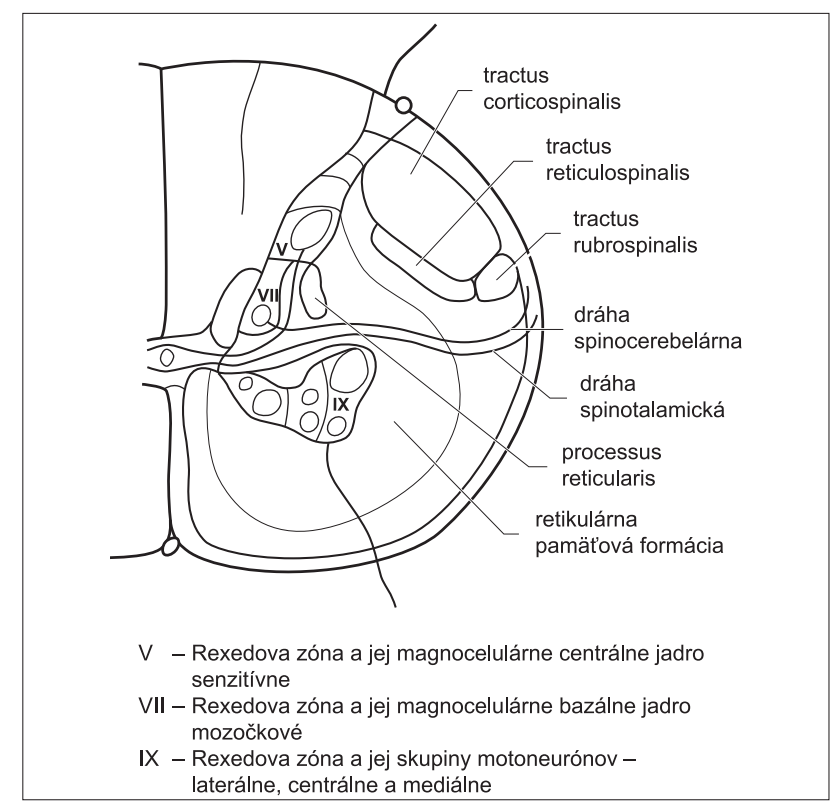

Fig. 1. The structure of small interconnected nerve cells forming a dense neural network. 


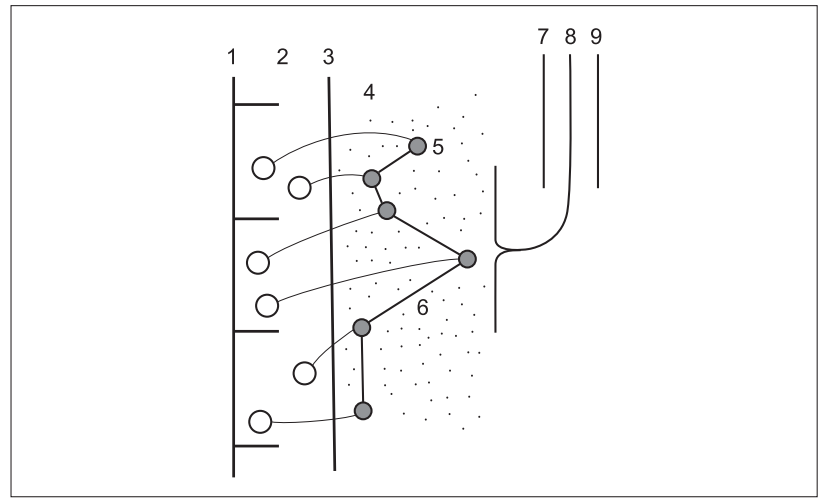

Figure 2.

The real perspective for the analysis and detailed understanding of spinal cord movement mechanisms is provided by the research in the field of spinal cord stereotaxy or microscopic analysis of post-traumatic changes of spinal cord structures and subsequent correlation with motor findings. The hypothetical analysis of the contemporary level of knowledge about the normal motor performance and the movement communication between brain and spinal cord also remain important steps.

Human motoneurons are star-shaped. Together with thicker fibres entering the anterior spinal motor root there are other fibres, e.g. those supplying spinal cord commissures located in the vicinity of the central canal (for mutual co-ordination of movements) or the group of magnocellular basal cells for spinocerebellar tracts in Rexed zone VII (for precise movements with their speed and power and possible participation in the pathophysiology of spaticity), for magnocellular central cells in Rexed zone $\mathrm{V}$ for sensitive spinothalamic tract (for movement evaluation in terms of correct or fault), or for the reticular processes in the middle of the lateral part of the butterfly-shaped spinal cord grey matter. From an anatomical view the reticular process contains short spinospinal tracts securing functional co-operation of the individual segments of the spinal cord bearing the name fasciculi proprii. The structure consists of small interconnected nerve cells forming a dense neural network (Figs 1-3).

From a mathematical point of view expressed by MSc. Kosorin, $\mathrm{PhD}$, from Slovak Academy of Science, this situation resembles the reticular memory system therefore leading to an idea that stimuli from the various motoneurons activated by movement are recorded in this system and according to the graph theory nodes and their connecting pathways are formed in the system. Therefore the "pathway" perceived as a picture (pattern) of the completed simple movement or the entire complex motor performance. Brain activities (analysis and synthesis) are closely related to it.

Under such circumstances the reticulospinal tract would only trasmit the picture of movements to the brain to be stored in the brain's memory as identical images or the movement might be verbally transformed into the name of the movement.

Therefore two different transformations are involved in movement: real movement from motoneurons to the reflex-

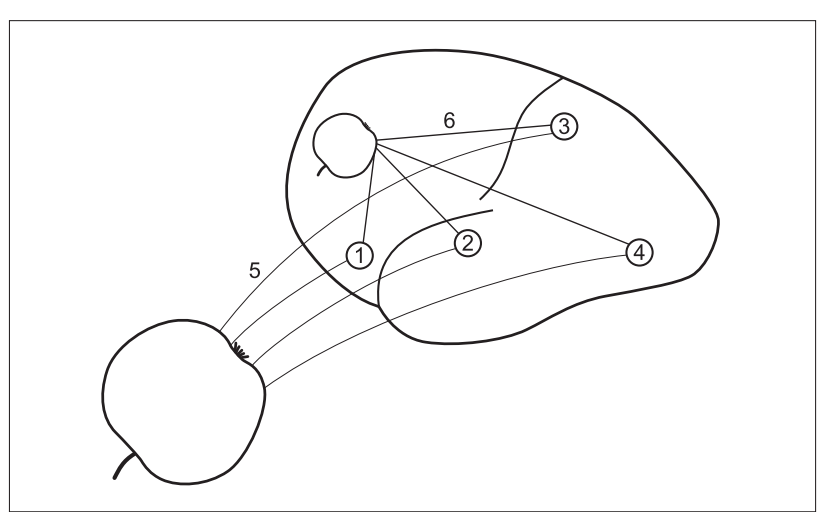

Figure 3.

ions in the spinal cord and from the transformed brain images to words.

Similar transformations take place also in the brain, when reality, e.g. an apple, is transformed by means of sensory functions into an abstract image (pattern), that is subsequently marked with a title in the brain. When a demand for movement repetition is formed in the brain, both transformation takes a contrary direction - from the brain to the spinal cord and to spinal cord motoneurons that are responsible for movement performance, possibly with the participation of corticospinal, rubrospinal and reticulospinal tracts. The initiation of movement can be therefore explained by physiological terms.

The explanation of movement restoration after a transverse spinal cord injury remains unexplained and hypothetical so far, but still hopeful, when respecting the above mentioned process of movement performance together with the experience obtained by I.P. Pavlov with complex stimuli. A functional conditioned connection between stimuli was established after repeated association of feeding stimulus with indifferent stimulus, manifesting as salivation in response to the different stimulus.

But Pavlov made an unexpected observation when a complex indifferent stimulus consisting of three tones forming cord was functionally connected with the feeding stimulus. Even when a single tone from this stimulation cord was presented to the animal the salivatory reaction was identical to the response after the complex stimulus.

The explanation is natural, because a human beings can be identified without direct observation. I tis sufficient simply to hear an individual's voice or to glimpse him walking.

Such a human being is a complex stimulus.

But movement is a complex stimulus, too, because of the participation of the various motoneurons from different spinal cord segments activated by the excitation of the proper neurons in the reticular memory of the spinal cord. The picture of a movement was realised by the connection and was subsequently transferred to the brain. Could it be a small or even minute part of the identical brain image entering the spinal cord which is sufficient to complete the movement picture by repeated stimuli and by the activation of the respective spinal cord motoneurons leading to movement restoration? 
When starting to walk triple flexion is the easiest lower limbs movement. This movement pattern is gradually permanently recorded in the memory of the spinal cord in the majority of animals, including humans. To elicit triple flexion in a patient paralysed beacuse of rigidity or spasticity it is necessary to irritate the plantar region. Is it possible to use, for instance, a moving belt providing repeated alternating tactile stimuli to the plantar area during walking rehabilitation? Do the identical movement patterns recorded in the spinal cord and in the brain still work? By means of reticulospinal tract or different mechanisms?

The lack of knowledge can be bridged only by research and tailored rehabilitation dealing with each restored movement element.

Therefore only a hypothetical idea about the mechanisms responsible for movement performance and restoration is available so far.

But this effort has been surpassed by modern technology developing robotic exoskeletons which are able to substitute walking restoration.
The idea, however, of physiological movement restoration was not interrupted and on the contrary new possibilties for movement restoration (functional electrical stimulation of the remaining spinal cord stem cells) in spinal cord injured patients are intensively explored.

\section{References}

1. Čierny G, Nádvorník P. Stereotactic atlas of the spinal cord. Bratislava: Kajan - Fekete, 2011

2. Zlatoš J. Topometria miechy člověka zameraná na cielené neurochirurgické zásahy. Doktorská dizertačná práca. Bratislava: LFUK, 1992, 182 pp.

3. Čierny G. Motorická lokalizácia v krčnej a hrudnej mieche mačky. Doktorská dizertačná práca. Bratislava: LFUK, 1983, 224 pp.

4. Davidson AG, Buford JA. Bilateral action of the reticulospinal tract on arms and shoulder muscles in the money. Stimulation triggered averaging. Exp Brain Res 2006; 173: 25 - 39 . 